\title{
Evaluación de los resultados de implementación del modelo de tutoría virtual
}

Evaluation of the Results of Implementation of the Virtual Tutoring Model

Avaliação dos resultados da implementação do modelo de tutoria virtual

Moramay Ramírez Hernández

Universidad Tecnológica de Tecámac, México

moramayrh@hotmail.com

https://orcid.org/0000-0003-3813-5149

Gabriela Figueroa Moreno

Universidad Tecnológica de Tecámac, México

gabifigmor@hotmail.com

https://orcid.org/0000-0002-8509-1305

Omar Téllez Barrientos

Universidad Tecnológica de Tecámac, México

omar_tellez76@hotmail.com

https://orcid.org/0000-0002-1109-2997 


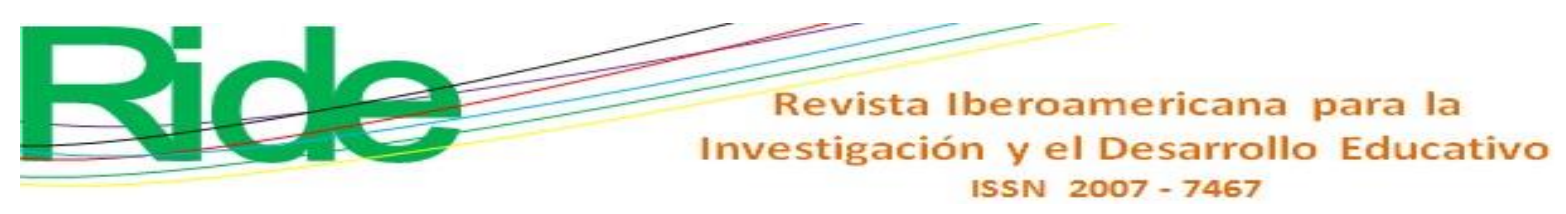

\section{Introducción}

La Universidad Tecnológica de Tecámac (Uttec) es un organismo público descentralizado del Gobierno del Estado de México. Fue creado en el año de 1996 con el objetivo de formar técnicos superiores universitarios e ingenieros aptos para la aplicación de conocimientos encaminados a la solución creativa de problemas en el sector productivo y a los requerimientos del desarrollo económico y social del estado y del país.

En esta institución se imparten once programas educativos de técnico superior universitario y ocho de nivel licenciatura. Y cuenta con una matrícula de más de 6000 estudiantes. No está de más señalar que, del total, cerca de $70 \%$ cursa estudios de nivel 5A, programas educativos reconocidos a nivel nacional por su buena calidad. En sus diferentes aulas, laboratorios y talleres se realizan actividades científicas.

Cuando se inició el pilotaje del proyecto de tutoría virtual en la carrera de Ingeniería en Tecnologías de la Información y Comunicación, en el cuatrimestre mayo-agosto 2018, se tenía una matrícula de 654 estudiantes: 269 técnicos superiores universitarios (de $1 .^{\circ}$ a $5 .^{\circ}$ cuatrimestre) y 218 de ingeniería (de $7 .^{\circ}$ a $10 .^{\circ}$ cuatrimestre). Cabe mencionar que este proyecto está orientado por el momento únicamente a los estudiantes de ingeniería, a saber: de $7 .^{\circ}$ a $10 .^{\circ}$ cuatrimestre, ya que en el $6 .^{\circ}$ y $11 .^{\circ}$ cuatrimestre se encuentran en una empresa o institución haciendo su estadía profesional.

Figueroa (2009) menciona que, dentro del contexto de las universidades tecnológicas, la tutoría responde a una característica inherente como parte de los servicios de acompañamiento al estudiante, con respecto a su inserción, adaptación y recorrido de su vida universitaria.

La Uttec, preocupada siempre por la mejora continua, ha implementado un modelo de tutorías presencial. Sin embargo, debido a las necesidades actuales de los estudiantes, específicamente de la Ingeniería en Tecnologías de la Información y de la Comunicación, se hace necesario buscar un esquema alternativo que permita a los estudiantes poder llevar a cabo esta labor sin que ello implique una mayor carga en sus horarios, de manera flexible, y que permita fortalecer su formación profesional.

Dadas las circunstancias que se estaban presentando con los estudiantes de dicha carrera, surge el proyecto de tutorías virtuales como una táctica para dar seguimiento a los estudiantes y como un medio de comunicación efectivo entre el tutor y sus tutorados. Para crear esta propuesta se trabajó con un grupo interdisciplinario de expertos que definió el modelo de tutoría virtual acorde a las principales problemáticas detectadas en la ingeniería, definiendo los objetivos que se 


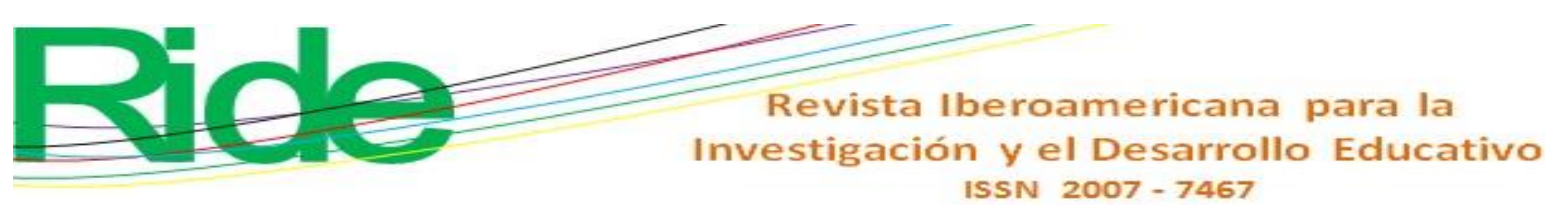

pretenden alcanzar en cada cuatrimestre, y, con base en ello, realizar tanto el diseño instruccional como los materiales.

Por otro lado, se propuso que, a través del entorno virtual, se les dé seguimiento a los tutores con el fin de mejorar su práctica, y encontrar las áreas de oportunidad que se tienen para que realmente la tutoría sea efectiva.

El presente artículo describe la evaluación de los resultados del ya mencionado modelo, que tiene tanto fundamentos tecnológicos como andragógicos, para el cual se realizó una investigación amplia y una propuesta de intervención que permitirá a la Uttec tener una alternativa tutorial bajo un enfoque nuevo, efectivo y con un impacto positivo entre los estudiantes de ingeniería, aprovechando por supuesto el uso de las tecnologías de la información y la comunicación (TIC).

\section{Objetivo}

Conocer los resultados de implementación del modelo de tutoría virtual generado mediante estrategias andragógicas y tecnológicas para fortalecer la formación profesional en la Ingeniería en Tecnologías de la Información y Comunicación de la Uttec.

\section{Pregunta de investigación}

¿Cómo evaluar la implementación del modelo de tutoría virtual para el fortalecimiento de la formación profesional en la Ingeniería en Tecnologías de la Información y Comunicación de la Uttec?

\section{Hipótesis}

La implementación de un modelo de tutoría virtual para los estudiantes de Ingeniería en Tecnologías de la Información y de la Comunicación fortalecerá su formación profesional.

\section{Estado del arte}

Las teorías de aprendizaje y acción tutorial fueron un referente importante durante el proceso de investigación de este proyecto. La teoría cognitiva de Ausubel (1976), por ejemplo, plantea que el proceso de enseñanza-aprendizaje debe llevarse en un ambiente creativo y de innovación. Con esta orientación, el interés reside en favorecer el desarrollo de los procesos 


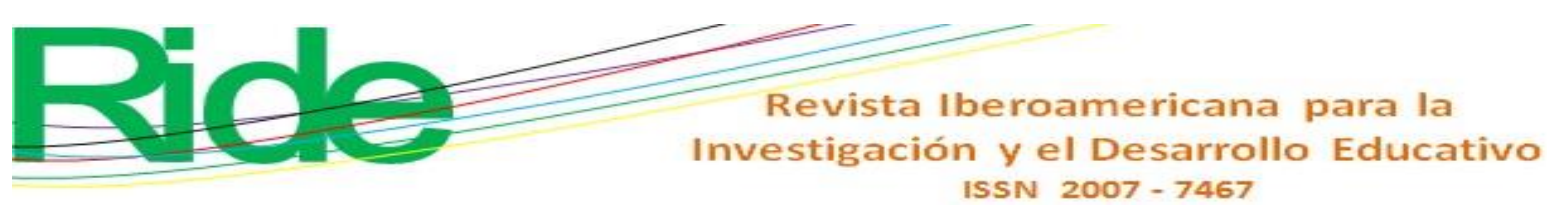

cognitivos y creativos, para que, posteriormente, el estudiante se desarrolle con autonomía e independencia en su práctica profesional, con sus propias innovaciones (aprendizaje autogestivo).

El aprender a aprender es clave para la acción tutorial, y retoma especial importancia al abordar el desarrollo de habilidades. En ese plano, los aprendizajes se conciben como la vinculación que hace el estudiante entre los conocimientos y las experiencias previas (Gairín, 2014). Por su parte, y retomando en esta perspectiva la concepción de aprendizaje, se entiende que este es el proceso activo de procesamiento y construcción mediante el cual el individuo adquiere destrezas o habilidades prácticas, así como incorpora contenidos informativos, o adopta nuevas estrategias de conocimiento o acción, valores y actitudes; además, es en esa adopción donde se comprueba que efectivamente se ha producido el aprendizaje (Pozo, 2009).

En la acción tutorial, el tutor promueve las habilidades de los estudiantes para procesar información; y ello constituye un factor fundamental para el desarrollo de las destrezas de comprensión, de aprendizaje y de retención. Al considerar que el alumno es un sujeto activo, sus procesos son enfatizados en las habilidades de procesamiento que despliega sobre la situación de aprendizaje; y se aleja cada vez más de la posición que concibe al estudiante como un receptor pasivo de la información. De tal manera que este, el aprendiz, se convierte en el centro de atención del tutor, y se le atribuye gran relevancia al análisis de todas aquellas actividades en las cuales se involucra, con el fin de adquirir, seleccionar, recordar, organizar e integrar el conocimiento. Los estudiantes, cuando reciben información nueva, la procesan, la almacenan y posteriormente la recuperan para aplicarla a nuevas situaciones de aprendizaje (Marroquín y Forzante, s. f.).

Asimismo, el estudiante desarrolla un aprendizaje que le facilita ejecutar actividades mentales más complejas, como las involucradas en el uso de estrategias cognitivas en la adquisición del conocimiento, en la solución de problemas y en los procesos de autorregulación. Si el tutor promueve y facilita en sus estudiantes el dominio de estrategias de aprendizaje, este podrá planificar y organizar sus propias actividades, que pueden ser técnicas o hábitos, y otras estrategias para su desarrollo (Rivas, 2000).

Ahora bien, diversos autores han definido el concepto de tutoría virtual. Sin embargo, muchos de ellos ven a la tutoría más bien como una asesoría académica. El concepto que más se acerca a lo que en la Uttec se ha implementado es el siguiente: 


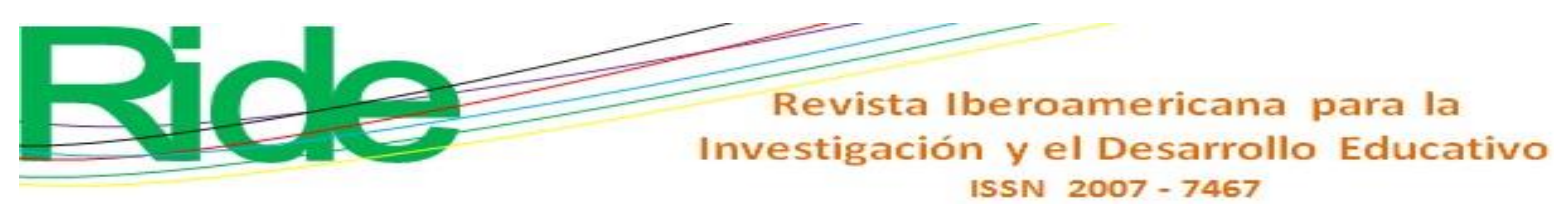

La tutoría virtual es clave en los procesos de enseñanza-aprendizaje de la modalidad a distancia, surge en un espacio de intercambio didáctico comunicativo entre estudiantes, docentes y docentes tutores que es la plataforma virtual, que a su vez, nos permite presentar un contexto práctico y cooperativo, posibilitar información a nuestros estudiantes y colegas profesores-tutores, armonizar los medios clásicos y virtuales, facilitar el desarrollo de tareas formativas, generar una comunidad de aprendizaje, desarrollar una función tutorial acorde al medio (Medina, Domínguez y Sánchez, 2011, p. 15).

Otro referente importante para este trabajo fue la parte andragógica, ya que los estudiantes de Ingeniería en Tecnologías de la Información y de la Comunicación son adultos. Bernard (1985, p.4) ve a la andragogía de la siguiente forma:

Una disciplina definida al mismo tiempo como una ciencia y un arte; una ciencia que trata los aspectos históricos, filosóficos, sociológicos, psicológicos y organizacionales de la educación de adultos; un arte ejercido en una práctica social que se evidencia gracias a todas las actividades educativas organizadas especialmente para el adulto.

\section{Metodología}

La presente investigación tuvo un enfoque mixto debido a que se combinó tanto el enfoque cuantitativo como cualitativo. Además, por el dinamismo del proyecto, la investigación utiliza tanto el esquema inductivo como el deductivo.

El diseño de investigación fue no experimental, pues no hay manejo y modificación de variables de investigación. Lo que se hace en la investigación no experimental es observar fenómenos tal y como se dan en su contexto natural para después analizarlos. Como señala Kerlinger (1979; citado en Ávila, 2006): “La investigación no experimental o ex profeso, es cualquier investigación en la que resulta imposible manipular variables o asignar aleatoriamente a los sujetos o a las condiciones" (p. 76).

Para el desarrollo de este proyecto, se decidió realizar un estudio de tipo exploratorio, ya que, según Hernández, Fernández y Baptista (2010): “Los estudios exploratorios se realizan cuando el objetivo es examinar un tema o problema de investigación poco estudiado, del cual se tienen muchas dudas, o no se ha abordado antes" (p. 79). 


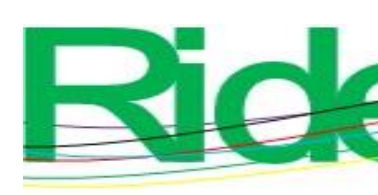

Revista Iberoamericana para la
Investigación y el Desarrollo Educativo
ISSN $2007-7467$

1) Problematización: En esta etapa se ordenaron, agruparon y relacionaron los datos de acuerdo con los objetivos de la investigación, preparando la información a fin de proceder a su análisis e interpretación, lo que permitió conocer la situación actual de la tutoría y con ello poder elaborar un diagnóstico.

2) Diagnóstico: Una vez que se identificó el problema, y habiendo formulado el enunciado del mismo, se recopiló la información. Esto consistió en recoger diversas evidencias, a través de diferentes técnicas de recolección de datos, y conocer el punto de vista de los actores implicados, en este caso en el proceso de tutoría.

Para lo anterior se diseñaron instrumentos que se emplearon para recolectar y almacenar la información, tales como cuestionarios y entrevistas, la matriz de fortalezas, oportunidades, debilidades y amenazas (FODA) y la revisión documental.

3) Diseño de una propuesta de cambio: En esta fase se consideraron las diversas alternativas de actuación y sus posibles consecuencias. Se realizó una reflexión prospectiva que permitió diseñar una propuesta de cambio y mejoramiento, y definir un diseño de evaluación de la misma. Esto se realizó con la intención de anticipar los indicadores y metas que se definieron en la propuesta.

4) Aplicación de propuesta: Después de diseñar la propuesta de acción del modelo de tutoría virtual, que fue llevada a cabo por las personas interesadas, se aplicó la propuesta realizada, lo que implicó una nueva forma de actuar, un esfuerzo de innovación y mejoramiento de la práctica docente, que, según el método, debe ser sometido permanentemente a condiciones de análisis, evaluación y reflexión.

5) Evaluación: Al final del proceso de investigación, se llevó a cabo la evaluación, a partir del cual se obtuvo una retroalimentación para mejorar el proyecto y con ello realizar los cambios que se requieran con el fin de ir mejorándolo. Serán la nueva situación y sus consecuencias las que determinen el proceso de investigación; y el probable inicio de otro ciclo en la espiral de la investigación-acción.

\section{Población y muestra}

La población contemplada para la evaluación fueron únicamente los 218 estudiantes de Ingeniería en Tecnologías de la Información y de la Comunicación inscritos en $7 .^{\circ}, 8 .^{\circ}, 9 .^{\circ}$ y $10 .^{\circ}$ cuatrimestre durante el periodo mayo-agosto 2018. 


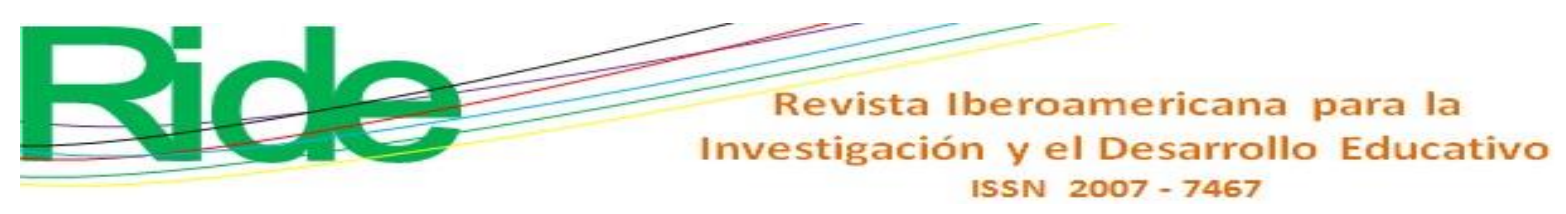

Para obtener parte de los resultados de implementación del modelo de tutoría virtual, y con la finalidad de identificar las áreas de oportunidad que los estudiantes de dicha carrera tienen en relación con la tutoría, se realizó una encuesta mediante la aplicación de cuestionarios.

Con la intención de generalizar a toda la población los resultados obtenidos, la muestra se realizó de manera representativa. Para ello el primer paso fue determinar el tamaño de la muestra. Esto depende de tres aspectos:

1) Error permitido.

2) Nivel de confianza estimado.

3) Carácter finito o infinito de la población.

En este caso, como ya se mencionó, la población está integrada de 218 estudiantes, por lo que se trata de una población finita (menos de 100 000). A sabiendas de lo anterior, se aplica la siguiente fórmula:

$$
n=\frac{Z^{2} * N * p * q}{E^{2}(N-1)+Z^{2} * p * q}
$$

En donde:

$n=$ Número de elementos de la muestra.

$N=$ Número de elementos de la población o universo. En este caso: 218 .

$p / q=$ Probabilidades con las que se presenta el fenómeno. En el presente estudio se tomó el caso más adecuado, es decir, aquel que necesite el máximo tamaño de la muestra, lo cual ocurre para $p=q=50$, luego $p=50$ y $q=50$.

$Z=$ Valor crítico correspondiente al nivel de confianza elegido. Aquí se desea un nivel de confianza de $95 \%$, al cual le corresponde un valor de $Z$ de 1.96 .

$\mathrm{E}=$ Margen de error permitido. En este caso se decidió tomar un margen de error de $5 \%$. Así, pues, sustituyendo lo anterior, se tiene:

$$
\begin{gathered}
n=\frac{(1.96)^{2} * 218 * .50 * .50}{.05^{2} *(218-1)+\left(1.96^{2}\right) * .50 * .50} \\
n=\frac{209.3672}{1.5028}=139.31
\end{gathered}
$$




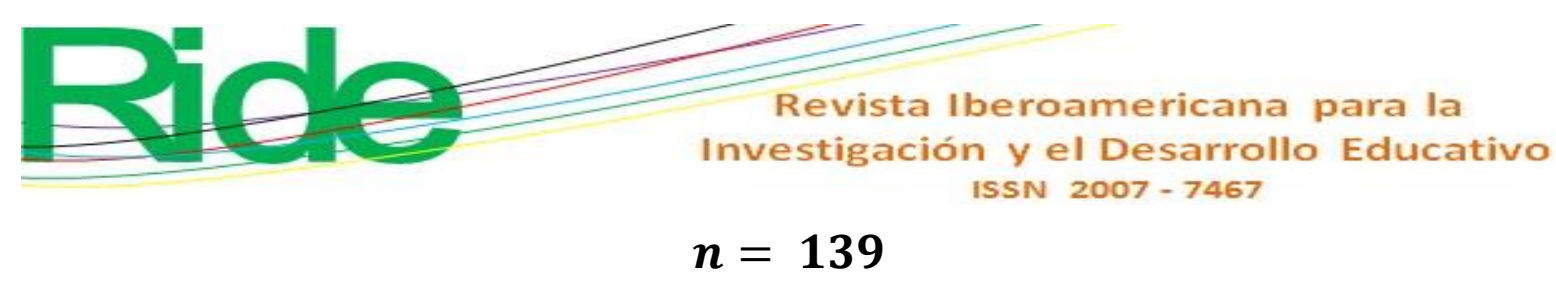

El segundo paso es el proceso de selección de la muestra, que está basado en el principio de aleatorización con la finalidad de darle fiabilidad a la encuesta. El muestreo que se utilizó en la presente investigación es el aleatorio ya que está basado en el azar y se caracteriza porque todos los elementos tienen siempre la misma probabilidad de resultar elegidos. Aún más: por la naturaleza de la investigación, se utilizó el muestreo aleatorio estratificado.

En este caso, la estratificación se hizo por programa educativo, y a su vez, por cuatrimestre, gracias a lo que se garantiza que la muestra tenga la misma composición que la población. En la tabla 1 se muestra la integración de la matrícula al inicio del cuatrimestre mayoagosto 2018 .

Tabla 1. Integración de la matrícula al inicio del cuatrimestre

\begin{tabular}{|c|c|c|c|c|c|}
\hline \multicolumn{6}{|c|}{ Matrícula cuatrimestre mayo-agosto 2018 } \\
\cline { 1 - 4 } Núm. & Grupo & H & M & Total & Total por cuatrimestre \\
\hline $\mathbf{1}$ & 7 ITI1 & 29 & 9 & 38 & 38 \\
\hline $\mathbf{2}$ & 8 ITI1 & 30 & 6 & 36 & 70 \\
\hline $\mathbf{3}$ & 8 ITI2 & 26 & 8 & 34 & 74 \\
\hline $\mathbf{4}$ & 9 ITI1 & 16 & 6 & 22 & \\
\hline $\mathbf{5}$ & 9 9ITI2 & 19 & 7 & 26 & 36 \\
\hline $\mathbf{6}$ & 9 9ITI3 & 18 & 8 & 26 & $\mathbf{2 1 8}$ \\
\hline $\mathbf{7}$ & 11 ITI1 & 20 & 16 & 36 & $\mathbf{2 1 8}$ \\
\hline \multicolumn{2}{|l|}{ Totales } & $\mathbf{1 5 8}$ & $\mathbf{6 0}$ & & \\
\hline
\end{tabular}

Fuente: Elaboración Propia

Con base en el tamaño de la muestra determinado (139 cuestionarios) y considerando los porcentajes anteriores, se determinaron el porcentaje y las muestras por cuatrimestre. Los resultados se presentan en la tabla 2. 


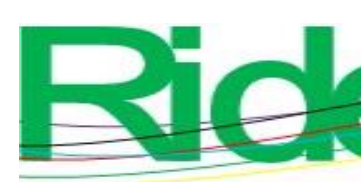

\section{Revista Iberoamericana para la Investigación y el Desarrollo Educativo ISSN $2007-7467$}

Tabla 2. Porcentaje y número de cuestionarios a aplicar por cuatrimestre.

\begin{tabular}{|l|c|c|c|c|c|}
\hline \multicolumn{1}{|c|}{ Carrera } & Séptimo & Octavo & Noveno & Décimo & TOTAL \\
\hline $\begin{array}{l}\text { Porcentaje de matrícula } \\
\text { de la Ingeniería en } \\
\text { Tecnologías de la } \\
\begin{array}{l}\text { Información y de la } \\
\text { Comunicación }\end{array}\end{array}$ & & $32 \%$ & $34 \%$ & $17 \%$ & $\mathbf{1 0 0 \%}$ \\
\hline $\begin{array}{l}\text { Número de } \\
\text { cuestionarios a aplicar }\end{array}$ & 24 & 44 & 47 & 24 & $\mathbf{1 3 9}$ \\
\hline
\end{tabular}

Fuente: Elaboración propia

\section{Modelo de tutoría virtual}

La propuesta de un modelo de tutoría virtual fue diseñada considerando principalmente las características y necesidades de los estudiantes de la ingeniería ya especificada. En la figura 2 se muestra dicho modelo.

Figura 2. Modelo de tutoría virtual

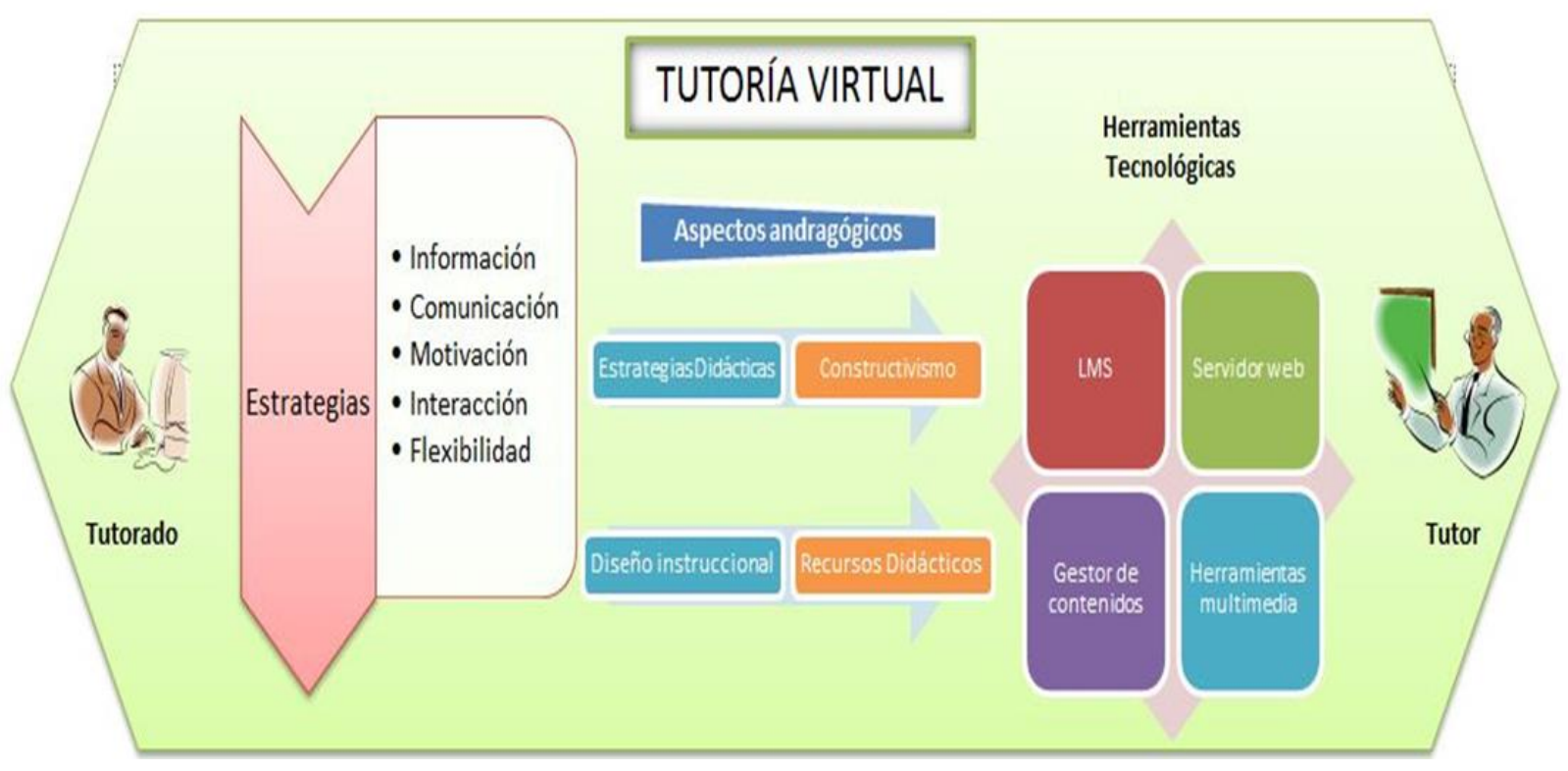

Fuente: Elaboración Propia 


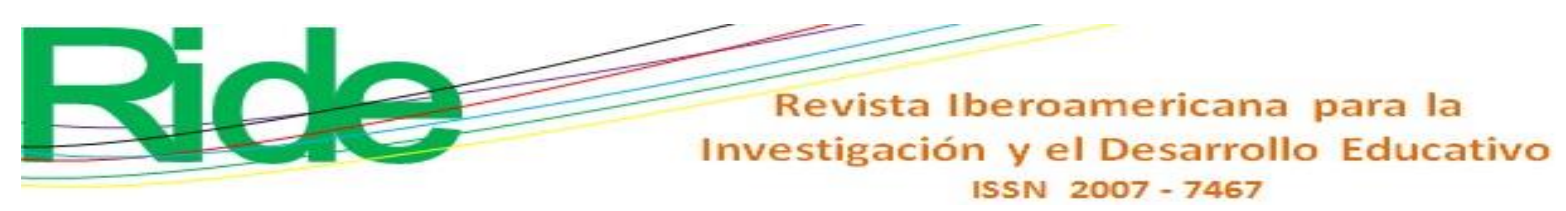

Como parte de los resultados importantes, está la detección de necesidades formativas, que se obtuvieron con base en los datos arrojados por los instrumentos aplicados. A partir de estas se definieron los contenidos para cada una de las tutorías. Se establecieron como metas generar la tutoría virtual para los siguientes cuatrimestres: $7 .^{\circ}, 8 .^{\circ}, 9 .^{\circ}$ y $10 .^{\circ}$, con el objetivo de cubrir a todos los estudiantes de la ingeniería. Es importante mencionar una vez más que no se consideró el $11 .^{\circ}$ semestre debido a que los estudiantes en este cuatrimestre se encuentran en estadía.

Se definió una temática general por cuatrimestre, el objetivo de la tutoría de cada cuatrimestre, y el número de sesiones, el cual quedó en 12, pues si bien el cuatrimestre tiene 15 semanas, las últimas dos son de evaluación, aunado a que se consideró iniciar a partir de la segunda semana. Así, pues, se consideró iniciar en la segunda y terminar dos semanas antes del cierre para todos los casos.

Cada sesión de tutoría está diseñada para trabajarse en una hora a la semana. Y el estudiante tiene la oportunidad de trabajarla cuando le sea más conveniente, con lo cual se flexibiliza el modelo tutorial. Las tutorías quedaron organizadas como se muestra en la tabla 3. 


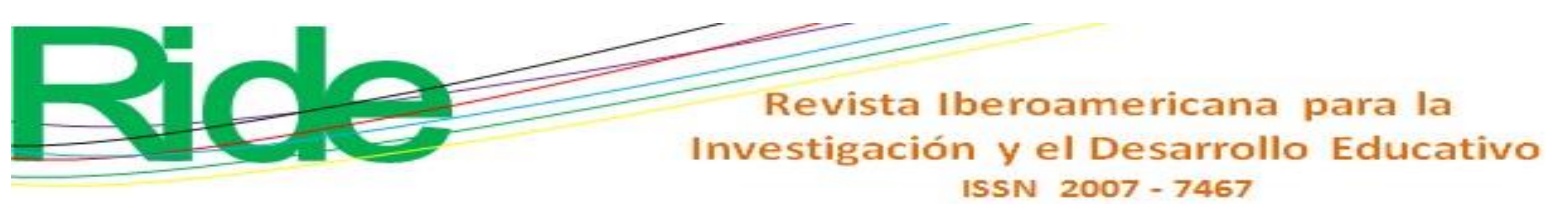

Tabla 3. Estructura general de la tutoría virtual

\begin{tabular}{|c|c|c|c|}
\hline Cuatrimestre & Temática & Objetivo & $\begin{array}{l}\text { Número } \\
\text { de } \\
\text { sesiones }\end{array}$ \\
\hline $7 .^{\circ}$ & Herramientas básicas & $\begin{array}{l}\text { Reflexionar sobre la importancia de } \\
\text { la tutoría virtual como una } \\
\text { herramienta introductoria a la } \\
\text { ingeniería, y conocer las habilidades } \\
\text { con que cuenta el estudiante para } \\
\text { enfrentarse a ella. }\end{array}$ & 12 \\
\hline $8 .^{\circ}$ & $\begin{array}{l}\text { Habilidades del } \\
\text { pensamiento }\end{array}$ & $\begin{array}{l}\text { Desarrollar las habilidades del } \\
\text { pensamiento del estudiante a través } \\
\text { de ejercicios que impacten de manera } \\
\text { positiva su desempeño escolar. }\end{array}$ & 12 \\
\hline $9 .^{\circ}$ & Imagen de sí mismo & $\begin{array}{l}\text { Desarrollar una imagen positiva de sí } \\
\text { mismo, que contribuya a un mejor } \\
\text { desempeño como profesional. }\end{array}$ & 12 \\
\hline $10 .^{\circ}$ & $\begin{array}{c}\text { Habilidades para el } \\
\text { éxito }\end{array}$ & $\begin{array}{l}\text { Desarrollar las habilidades necesarias } \\
\text { que favorezcan su formación como } \\
\text { profesional competitivo. }\end{array}$ & 12 \\
\hline
\end{tabular}

Fuente: Elaboración propia

A partir de lo anterior, se implementó el modelo y contenidos en la plataforma virtual de la Uttec, tal y como se muestra en la figura 3. 


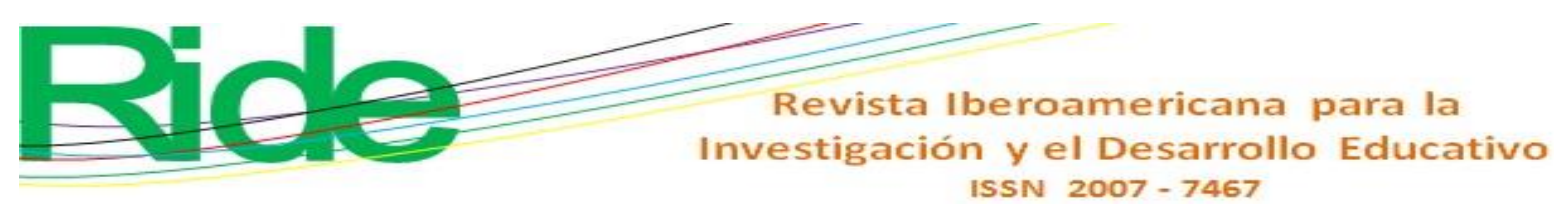

Figura 3. Sitio de tutoría virtual

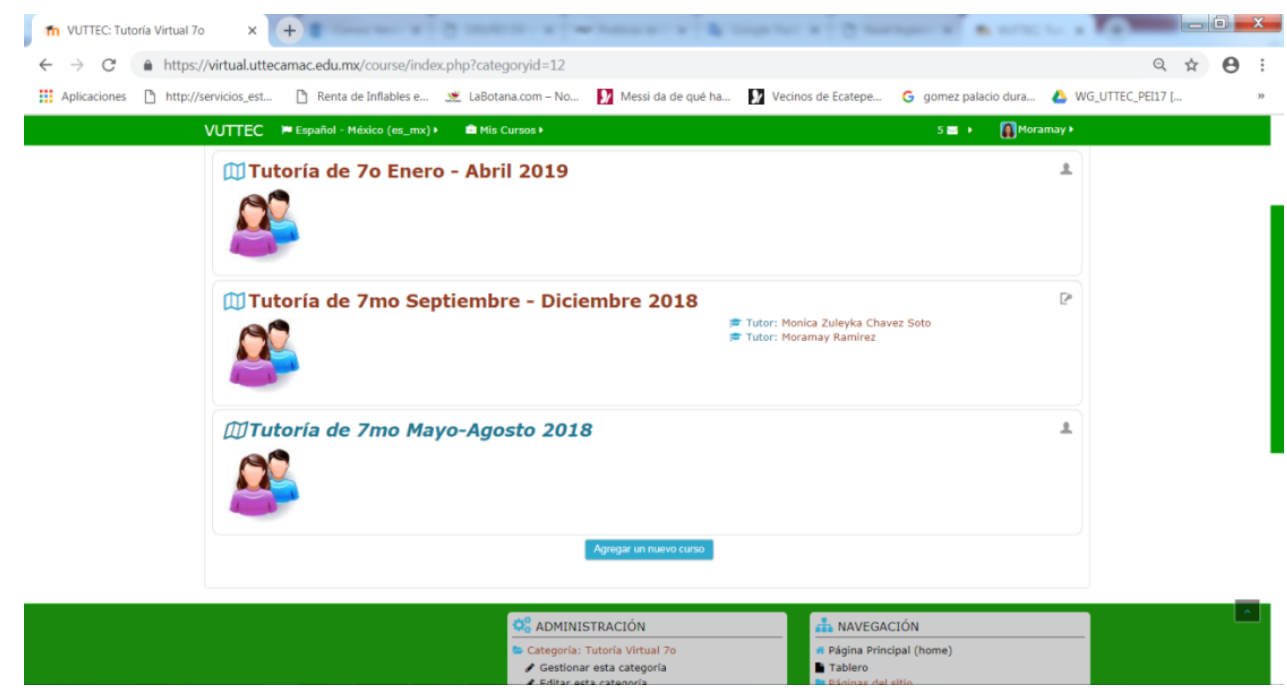

Fuente: Elaboración propia

Para la evaluación de los resultados de la implementación del modelo de tutoría virtual se aplicaron 3 instrumentos. El primer instrumento fue aplicado a los integrantes del Cuerpo Académico de Tutorías. El segundo instrumento a los estudiantes tutorados. Y el último fue una revisión de datos estadísticos.

\section{Instrumento 1. Evaluación del proceso continuo}

Para la parte de evaluación del proceso se tomó en cuenta la guía de preguntas de Cookson (2003). Esta fue respondida por los cinco expertos del Cuerpo Académico de Tutorías (ver tabla 4). 


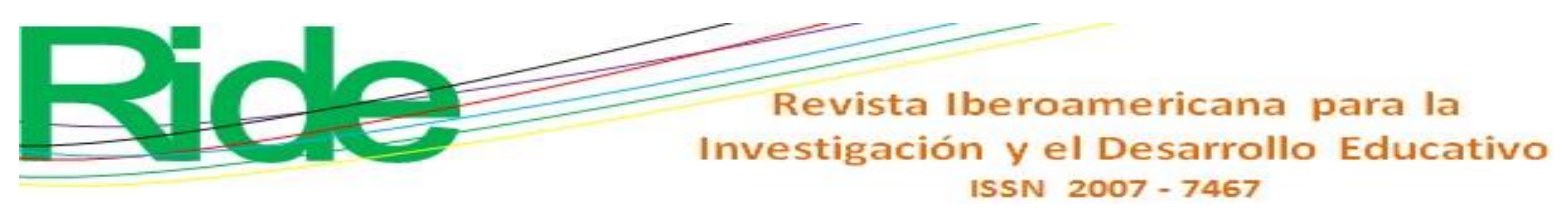

Tabla 5. Dimensiones de la evaluación del proceso continuo

\begin{tabular}{|l|l|c|}
\hline \multicolumn{1}{|c|}{ Núm. de dimensión } & \multicolumn{1}{|c|}{ Dimensiones } & $\begin{array}{c}\text { Núm. de } \\
\text { ítems }\end{array}$ \\
\hline 1 & Plataforma & 2 \\
\hline 2 & Modalidad virtual & 3 \\
\hline 3 & Contenidos & 4 \\
\hline 4 & Desempeño de tu tutor & 9 \\
\hline 5 & Programa de tutoría & 3 \\
\hline
\end{tabular}

Fuente: Elaboración Propia

Para complementar se hicieron cuatro preguntas abiertas enfocadas a sugerencias, mejoras y comentarios generales.

\section{Instrumento 3. Revisión de datos}

La revisión de fuentes escritas que guardan estrecha relación con el propósito del estudio fue muy importante para el proyecto. Para la presente investigación, el procesamiento de datos es una actividad que implica un conjunto de manipulaciones, transformaciones, reflexiones y comprobaciones a partir de los datos recopilados con el fin de extraer significados relevantes para el estudio.

La Uttec cuenta con un sistema automatizado donde se concentra la información estadística de los estudiantes. De allí se tomaron los datos que se consideraron importantes para un razonamiento deductivo de los resultados de la aplicación del proyecto, considerando aprobación, reprobación, promedios y deserción escolar, tomando como referencia los periodos comprendidos desde que se realizó el diagnóstico hasta que se piloteó. 


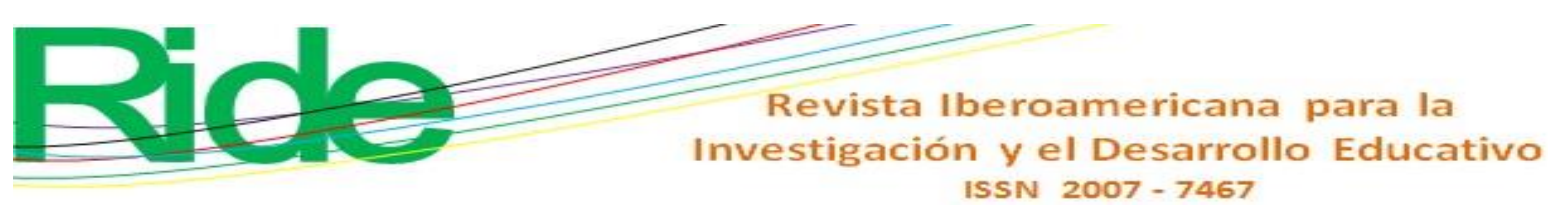

\section{Resultados}

\section{Análisis del instrumento 1. Evaluación del proceso continuo}

Como ya se comentó, este instrumento se aplicó a cinco integrantes del Cuerpo Académico de Tutorías. Se obtuvieron los resultados que se presentan en la tabla 6.

Tabla 6. Resultados de la evaluación del proceso continuo

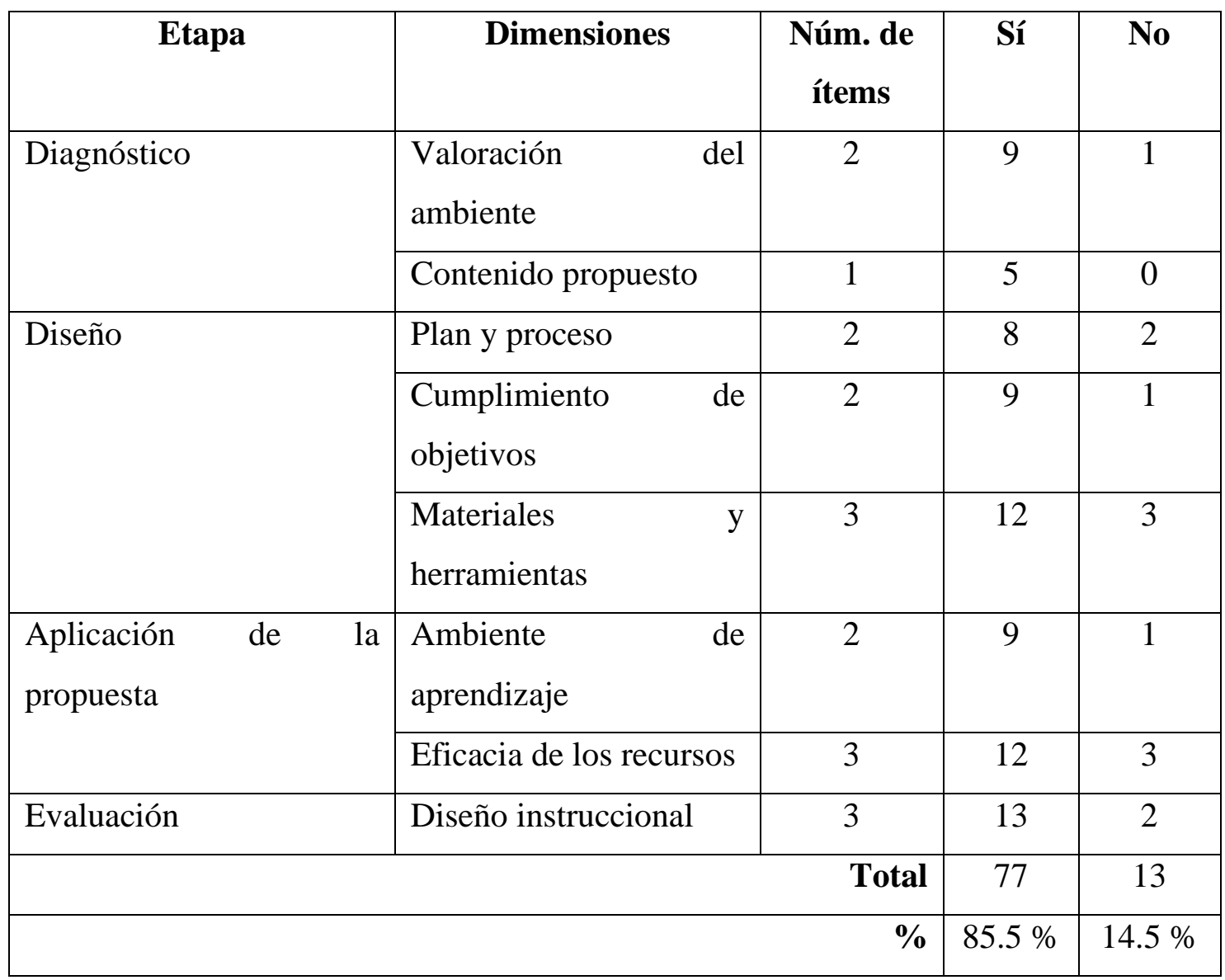

Fuente: Elaboración propia

Como se puede observar, la mayoría de los resultados son positivos, ya que se cumple en $85.5 \%$. Sin embargo, hay áreas de oportunidad para mejorar, como son las dimensiones de Materiales y herramientas y Eficacia de los recursos.

\section{Análisis del instrumento 2. Evaluación de la tutoría virtual}

Tal cual se menciona líneas arriba, el pilotaje de este proyecto se realizó en el cuatrimestre mayo-agosto del 2018 , con estudiantes de $7 .^{\circ}, 8 .^{\circ}, 9 .^{\circ}$ y $10 .^{\circ}$ cuatrimestre de la carrera de Ingeniería en Tecnologías de la Información y de la Comunicación, con la intención de retroalimentar los resultados y mejorar el modelo. 


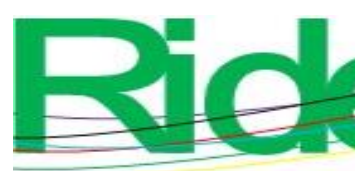

Revista Iberoamericana para la Investigación y el Desarrollo Educativo

ISSN 2007 - 7467

La encuesta fue aplicada a 139 estudiantes que llevaron la tutoría virtual. La tabla 7 muestra los resultados de las encuestas aplicadas.

Tabla 7. Resultados de la evaluación de los estudiantes

\begin{tabular}{|c|c|c|c|c|}
\hline Núm. & Pregunta & $\begin{array}{l}\text { Totalmente } \\
\text { de acuerdo } \\
\qquad(\%)\end{array}$ & $\begin{array}{l}\text { Ni de } \\
\text { acuerdo ni } \\
\text { en } \\
\text { desacuerdo } \\
\quad(\%)\end{array}$ & $\begin{array}{l}\text { Totalmente } \\
\text { en } \\
\text { desacuerdo } \\
(\%)\end{array}$ \\
\hline 1 & $\begin{array}{c}\text { ¿La modalidad de tutoría virtual te pareció } \\
\text { adecuada para para tu formación } \\
\text { profesional? }\end{array}$ & $76 \%$ & $22 \%$ & $3 \%$ \\
\hline 2 & ¿El uso de la plataforma fue sencillo? & $54 \%$ & $43 \%$ & $3 \%$ \\
\hline 3 & ¿El diseño de la plataforma es atractivo? & $62 \%$ & $19 \%$ & $19 \%$ \\
\hline 4 & $\begin{array}{l}\text { ¿Realizaste algunas de las actividades } \\
\text { semanales? }\end{array}$ & $70 \%$ & $27 \%$ & $3 \%$ \\
\hline 5 & $\begin{array}{l}\text { ¿La velocidad para consultar la plataforma y } \\
\text { resolver los ejercicios es adecuada? }\end{array}$ & $32 \%$ & $46 \%$ & $22 \%$ \\
\hline 6 & $\begin{array}{l}\text { ¿Los contenidos te fueron interesantes para } \\
\text { tu desempeño académico? }\end{array}$ & $62 \%$ & $35 \%$ & $3 \%$ \\
\hline 7 & $\begin{array}{c}\text { ¿Aplicaste algo de lo visto en la tutoría } \\
\text { virtual en tu vida diaria? }\end{array}$ & $51 \%$ & $46 \%$ & $3 \%$ \\
\hline 8 & $\begin{array}{c}\text { ¿Los ejercicios aplicados en tutoría virtual } \\
\text { los consideras adecuados para mejorar tu } \\
\text { desempeño académico? }\end{array}$ & $70 \%$ & $14 \%$ & $16 \%$ \\
\hline 9 & $\begin{array}{l}\text { ¿Las instrucciones para realizar las } \\
\text { actividades te resultaron claras? }\end{array}$ & $65 \%$ & $27 \%$ & $8 \%$ \\
\hline 10 & ¿Mostró buena disposición para apoyarte? & $76 \%$ & $22 \%$ & $3 \%$ \\
\hline 11 & $\begin{array}{c}\text { ¿Mostró interés en tu desempeño } \\
\text { académico? }\end{array}$ & $76 \%$ & $22 \%$ & $3 \%$ \\
\hline 12 & $\begin{array}{c}\text { ¿Te motivó a utilizar el esquema virtual de } \\
\text { tutorías? }\end{array}$ & $78 \%$ & $19 \%$ & $3 \%$ \\
\hline 13 & $\begin{array}{c}\text { ¿Te apoyó para identificar tus dificultades } \\
\text { académicas? }\end{array}$ & $59 \%$ & $38 \%$ & $3 \%$ \\
\hline 14 & $\begin{array}{c}\text { ¿Existió un canal de comunicación adecuado } \\
\text { entre tu tutor y tú? }\end{array}$ & $78 \%$ & $19 \%$ & $3 \%$ \\
\hline 15 & $\begin{array}{c}\text { ¿Respondió tus dudas de manera clara y } \\
\text { rápida? }\end{array}$ & $76 \%$ & $22 \%$ & $3 \%$ \\
\hline 16 & $\begin{array}{c}\text { ¿Fue sencillo localizar a tu tutor de manera } \\
\text { presencial? }\end{array}$ & $73 \%$ & $24 \%$ & $3 \%$ \\
\hline 17 & $\begin{array}{c}\text { ¿Te brindó información oportuna hacia algún } \\
\text { servicio de apoyo (servicio médico, servicios } \\
\text { estudiantiles, extensión universitaria, otro)? } \\
\text { Solo responde si requeriste alguna } \\
\text { canalización. }\end{array}$ & $70 \%$ & $24 \%$ & $5 \%$ \\
\hline
\end{tabular}




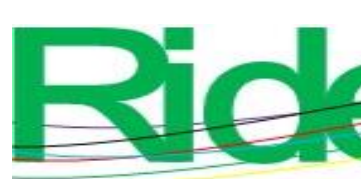

Revista Iberoamericana para la Investigación y el Desarrollo Educativo

ISSN 2007 - 7467

\begin{tabular}{|c|c|c|c|c|}
\hline 18 & $\begin{array}{l}\text { ¿Te canalizó oportunamente a alguno de los } \\
\text { servicio de apoyo (servicio médico, servicios } \\
\text { estudiantiles, extensión universitaria, otro)? } \\
\text { Solo responde si requeriste la canalización. }\end{array}$ & $73 \%$ & $22 \%$ & $5 \%$ \\
\hline 19 & $\begin{array}{l}\text { ¿Tu participación en el programa de tutoría } \\
\text { virtual ha mejorado tu desempeño } \\
\text { académico? }\end{array}$ & $46 \%$ & $51 \%$ & $3 \%$ \\
\hline 20 & $\begin{array}{l}\text { ¿Consideras que la tutoría favorece tu } \\
\text { formación personal y profesional? }\end{array}$ & $70 \%$ & $27 \%$ & $3 \%$ \\
\hline \multirow[t]{2}{*}{21} & $\begin{array}{c}\text { ¿Tu integración a la universidad ha mejorado } \\
\text { con el programa de tutoría virtual? }\end{array}$ & $62 \%$ & $35 \%$ & $3 \%$ \\
\hline & $\%$ & $65.57 \%$ & $28.72 \%$ & $5.71 \%$ \\
\hline
\end{tabular}

Fuente: Elaboración propia

Como se puede apreciar, $65.57 \%$ de los estudiantes tutorados que participaron en el pilotaje de la plataforma de tutoría virtual en el cuatrimestre mayo-agosto 2018 está totalmente de acuerdo con esta modalidad; $28.72 \%$ ni acuerdo ni en desacuerdo, y $5.71 \%$ totalmente en desacuerdo. Por lo que, a partir de los resultados, se revisó y se identificó que las áreas con mayor oportunidad son las siguientes:

- La velocidad de la plataforma. En este sentido se trabajará con la institución para mejorar el ancho de banda del servicio, pero también depende de la velocidad que tengan en sus hogares los estudiantes.

- Desempeño académico. Actualizar las sesiones para impactar en mayor medida y mejorar el desempeño académico, relacionándolas con las asignaturas de menor aprovechamiento académico.

- Dificultades académicas. Incluir más actividades que les ayuden a los tutorados a identificar claramente sus necesidades académicas

- Mejora continua de la tutoría virtual. Aunado a lo anterior, se procurará mejorar los resultados de esta primera evaluación realizada, sobre todo motivando a los tutores a desempeñar mejor su labor y actualizando periódicamente la plataforma.

Cabe resaltar que los resultados de la pregunta 20 respecto al fortalecimiento de la formación personal y profesional: 70 \% está totalmente de acuerdo con que sí se están fortaleciendo.

Respecto a las aportaciones que se hicieron de las cuatro preguntas abiertas, se analizarán junto con el cuerpo académico de tutorías y se considerarán las sugerencias que sean pertinentes para la siguiente actualización del trabajo. La tabla 8 muestra la lista de comentarios. 


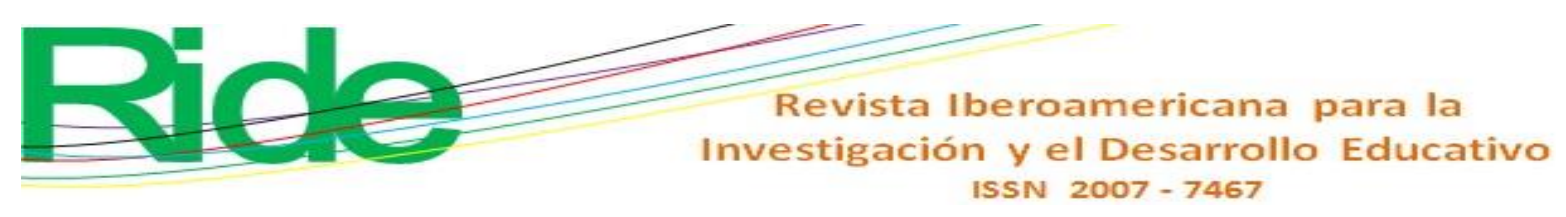

Tabla 8. Comentarios por parte de los estudiantes

\begin{tabular}{|c|c|c|}
\hline Categoría & Pregunta & Comentarios \\
\hline $\begin{array}{l}\text { Diseño y } \\
\text { usabilidad }\end{array}$ & $\begin{array}{l}\text { Si se } \\
\text { considerara } \\
\text { algún } \\
\text { cambio al } \\
\text { diseño y } \\
\text { manejo de la } \\
\text { plataforma } \\
\text { de tutoría } \\
\text { virtual, ¿cuál } \\
\text { (es) sería } \\
\text { (n)? }\end{array}$ & 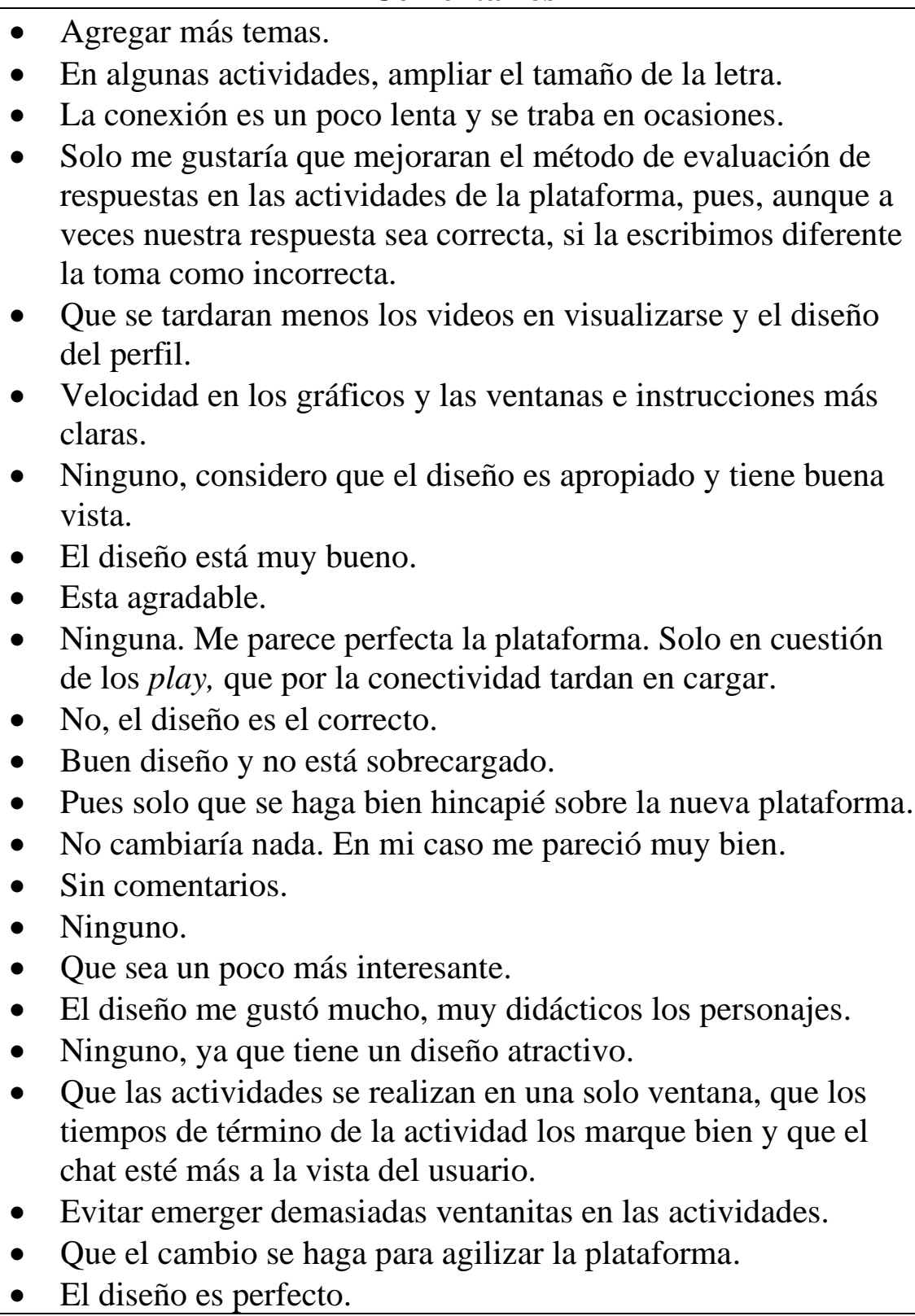 \\
\hline Contenido & $\begin{array}{l}\text { ¿Qué } \\
\text { sugerencias } \\
\text { harías para } \\
\text { mejorar el } \\
\text { contenido } \\
\text { del programa } \\
\text { de tutoría } \\
\text { virtual? }\end{array}$ & $\begin{array}{l}\text { - Más actividades interactivas. } \\
\text { - } \text { Que pongan más sencilla la ruta de las actividades. } \\
\text { - Mejorar el diseño de la página. } \\
\text { - } \text { Ningunar la velocidad cuando cargan las sesiones o actividades. } \\
\text { - El contenido es útil. } \\
\text { - Ninguno. Los temas que se aportan son los adecuados. } \\
\text { - Nada. } \\
\text { - Más imágenes, menos lectura en algunas diapositivas. } \\
\text { - } \quad \text { Mo forzar temas o artréculos de das actividades. } \\
\text { - }\end{array}$ \\
\hline
\end{tabular}




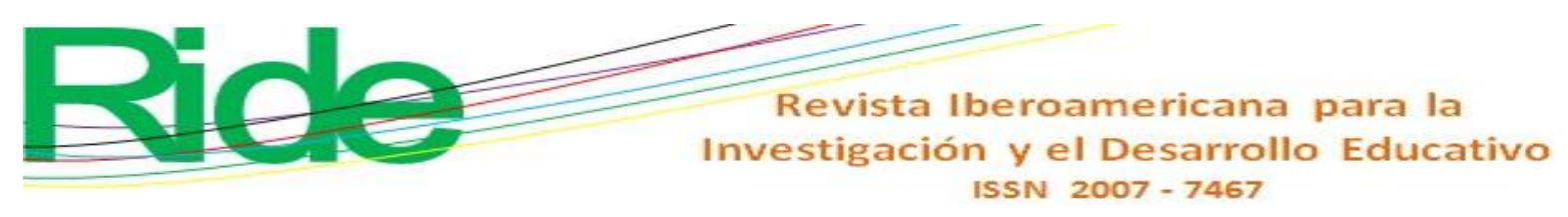

\begin{tabular}{|c|c|c|}
\hline & & $\begin{array}{l}\text { - Los temas me ayudaron en otras materias. } \\
\text { - } \text { Que añadan más temas. Son buenos los que contiene pero aún } \\
\text { - Sin comentación. } \\
\text { - Que no sea tanta teoría. } \\
\text { - Los temas son buenos. } \\
\text { - Cuando terminemos algún ejercicio, que el programa lo } \\
\text { marque como resuelto, y nos redireccione a los que nos falta } \\
\text { por resolver. } \\
\text { - } \text { Ee gustaron los temas son atractivos y útiles para nosotros. } \\
\text { - modificación, ya que los temas son atractivos. }\end{array}$ \\
\hline Interés & $\begin{array}{l}\text { ¿Qué temas } \\
\text { serían de tu } \\
\text { interés para } \\
\text { tratar en } \\
\text { tutoría } \\
\text { virtual? }\end{array}$ & 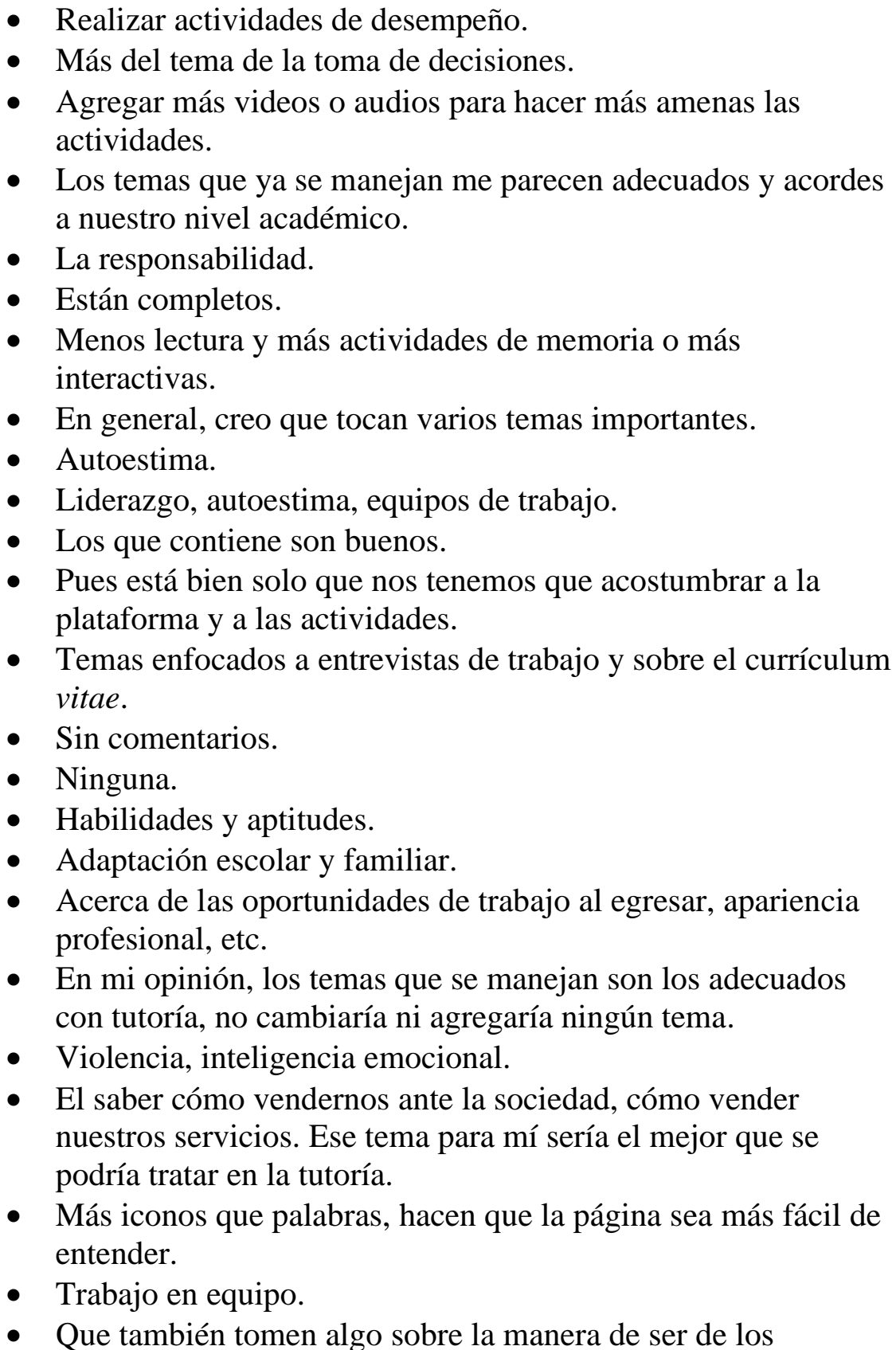 \\
\hline
\end{tabular}




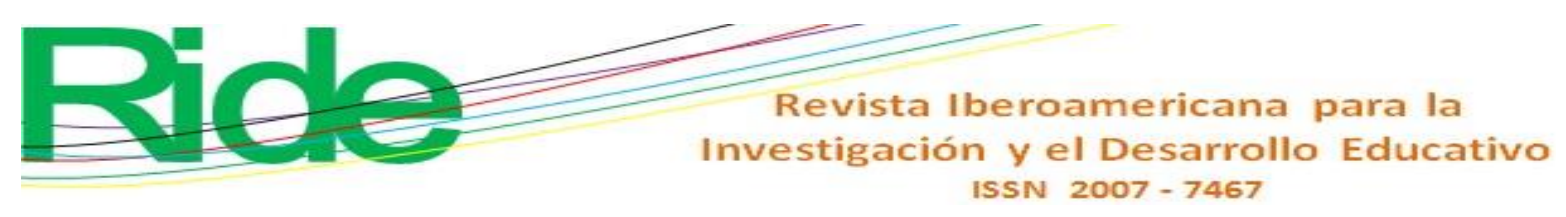

\begin{tabular}{|c|c|c|}
\hline & & $\begin{array}{l}\text { alumnos. } \\
\text { - Desarrollo de equipos de trabajo. }\end{array}$ \\
\hline General & $\begin{array}{l}\text { Comentario } \\
\text { general }\end{array}$ & 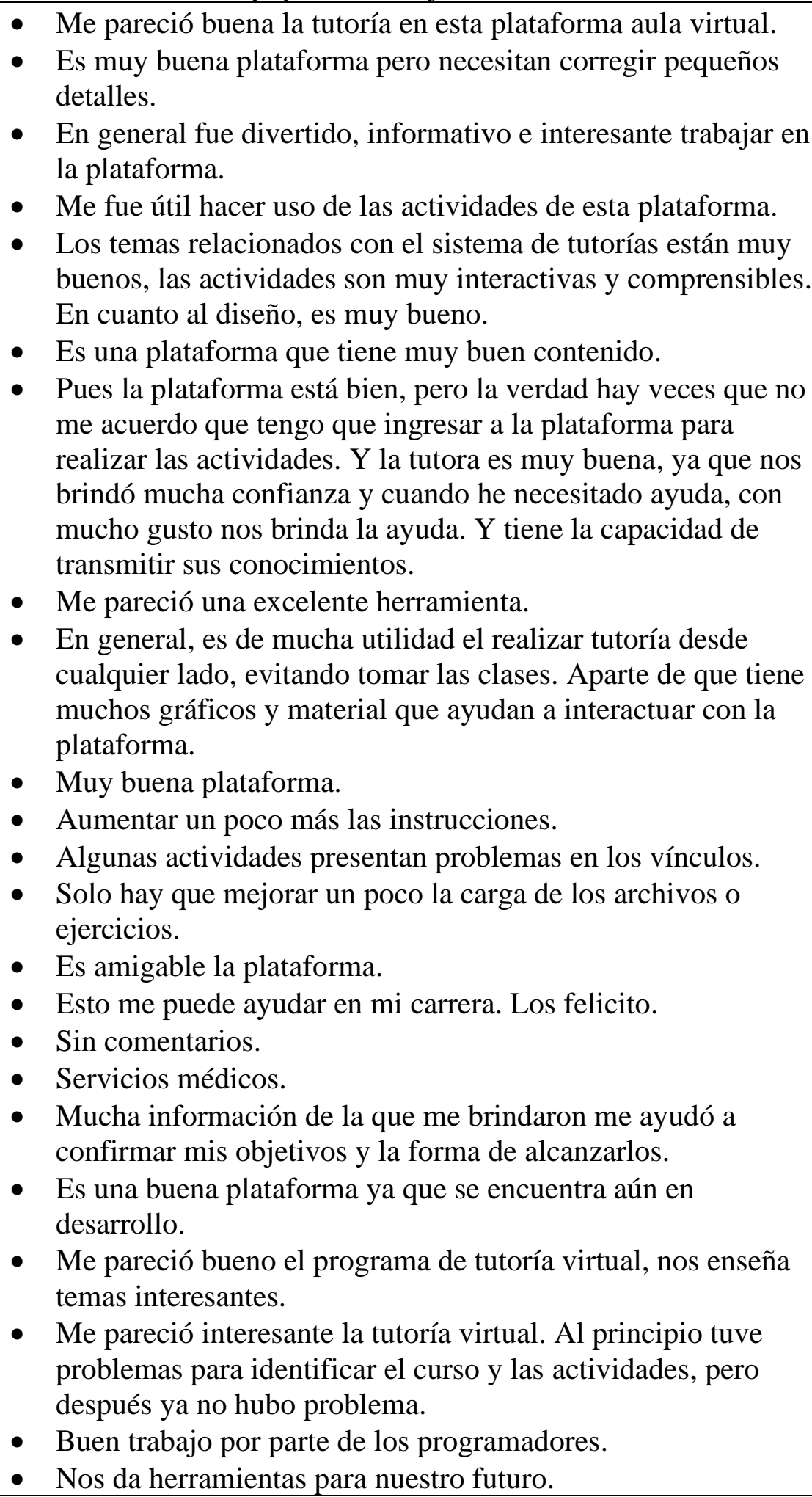 \\
\hline
\end{tabular}

Fuente: Elaboración propia 


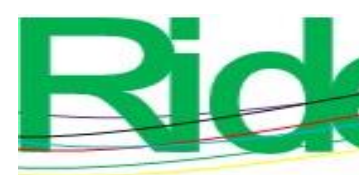

\section{Revista Iberoamericana para la Investigación y el Desarrollo Educativo ISSN $2007-7467$}

Cabe mencionar que los resultados y aportaciones recabados se tomarán en cuenta para la mejora continua y actualización del proyecto, principalmente mejorando los aspectos de diseño, contenidos y usabilidad, que está altamente ligada a la satisfacción y comodidad percibida por el usuario final (Ramírez, Téllez y Díaz, 2014). Se considera que hay comentarios muy positivos por parte de los estudiantes, tales como: "Los temas me ayudaron en otras materias", "Los temas son atractivos y útiles", "Esto me puede ayudar en mi carrera" o "Nos enseñan temas interesantes". Sin duda es un reflejo de que se está fortaleciendo su formación profesional. Sin embargo, también se detectan nuevas necesidades y temas que les interesan a los estudiantes: "violencia", "inteligencia emocional" y "trabajo en equipo", los cuales serán tomados en cuenta para la actualización de contenidos.

\section{Análisis del instrumento 3. Revisión de datos}

Para poder contrastar los resultados obtenidos con la implementación del modelo de la tutoría virtual, se extrajeron los datos del sistema de información de la Uttec, considerando la generación del pilotaje (mayo-agosto 2018) y tres generaciones anteriores. La tabla 9 muestra los resultados.

Tabla 9. Resultados estadísticos

\begin{tabular}{|l|c|r|r|r|r|r|r|}
\hline $\begin{array}{c}\text { Cuatrimestr } \\
\mathbf{e}\end{array}$ & $\begin{array}{c}\text { Matrícul } \\
\mathbf{a}\end{array}$ & $\begin{array}{c}\text { Promedi } \\
\mathbf{0}\end{array}$ & $\begin{array}{c}\text { Núm. de } \\
\text { aprobados }\end{array}$ & $\begin{array}{c}\text { Núm. de } \\
\text { reprobados }\end{array}$ & $\begin{array}{c}\text { Aprobados } \\
(\boldsymbol{\%})\end{array}$ & $\begin{array}{c}\text { Reprobados } \\
(\boldsymbol{\%})\end{array}$ & $\begin{array}{c}\text { Deserción } \\
(\boldsymbol{\%})\end{array}$ \\
\hline $\begin{array}{l}\text { May-Ago } \\
2017\end{array}$ & 183 & 8.15 & 172 & 11 & 93.98 & 6.02 & 0.00 \\
\hline $\begin{array}{l}\text { Sep-Dic } \\
2017\end{array}$ & 228 & 8.08 & 212 & 15 & 92.98 & 7.02 & 0.44 \\
\hline $\begin{array}{l}\text { Ene-Abr } \\
2018\end{array}$ & 247 & 7.96 & 215 & 32 & 87.04 & 12.96 & 0.00 \\
\hline $\begin{array}{l}\text { May-Ago } \\
2018\end{array}$ & 218 & 8.10 & 199 & 19 & 91.28 & 8.72 & 0.00 \\
\hline \begin{tabular}{l} 
Promedio \\
\hline
\end{tabular} & $\mathbf{2 1 9}$ & $\mathbf{8 . 0 7}$ & $\mathbf{1 9 9 . 5}$ & $\mathbf{1 9 . 2 5}$ & $\mathbf{9 1 . 3 2}$ & $\mathbf{7 . 6 3}$ & $\mathbf{0 . 1 1}$ \\
\hline
\end{tabular}

Fuente: Elaboración propia 


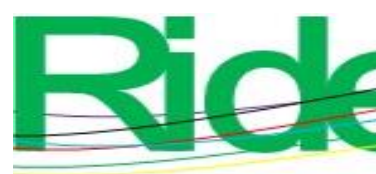

Revista Iberoamericana para la Investigación y el Desarrollo Educativo

ISSN $2007-7467$

Como se puede apreciar en la tabla anterior, si bien los resultados del cuatrimestre mayoagosto 2018 se mantienen muy cerca del promedio, hay una mejoría con respecto al cuatrimestre anterior: se incrementó el promedio y el número de aprobados, por lo que se puede deducir que la tutoría virtual está dando resultados similares a la tutoría presencial de los cuatrimestres anteriores.

\section{Discusión}

La tutoría virtual se da en un proceso enseñanza-aprendizaje, y efectivamente, como lo menciona la teoría cognitiva de Ausubel (1976), requiere de un ambiente creativo y de innovación, con el fin de favorecer el desarrollo de los procesos cognitivos y creativos, para que, posteriormente, el estudiante se desarrolle con autonomía e independencia en su práctica profesional. Lo anterior no es otra cosa que lo que persigue la implementación de este modelo en la Uttec, aprovechando el uso de las TIC.

De acuerdo con Marroquín y Forzante (s. f.), los estudiantes, cuando reciben información nueva, la procesan, la almacenan y posteriormente la recuperan para aplicarla a nuevas situaciones de aprendizaje. Y esto se pudo comprobar, ya que, aunque aún los estudiantes de Ingeniería en Tecnologías de la Información y de la Comunicación no están en un ámbito laboral, se aprecia que esta modalidad de tutoría virtual es una alternativa que presenta resultados similares respecto a la presencial.

En esa misma tónica, fue de gran utilidad la perspectiva de Pozo (2009) sobre la concepción de aprendizaje como proceso activo de procesamiento y construcción, mediante el cual el individuo adquiere destrezas o habilidades prácticas, ya que en este proyecto se agregaron actividades de cierre que permitieron validar que efectivamente se produjo aprendizaje.

Para la Uttec, a raíz de este proyecto, la tutoría virtual se ha convertido en un proceso de apoyo, guía, orientación y acompañamiento para los tutorados, principalmente para complementar su formación profesional y para alcanzar diferentes objetivos definidos en cada nivel de tutoría y en cada sesión (Ramírez et al., 2018).

Sin embargo, cabe recalcar que no se pretende sustituir la tutoría presencial, sino más bien tener una alternativa cuando así sea conveniente. Además, considerando que se está en un proceso iterativo e incremental a partir de los datos obtenidos, se tomarán acciones para mejorar el proyecto y, por consiguiente, los resultados de los estudiantes. 


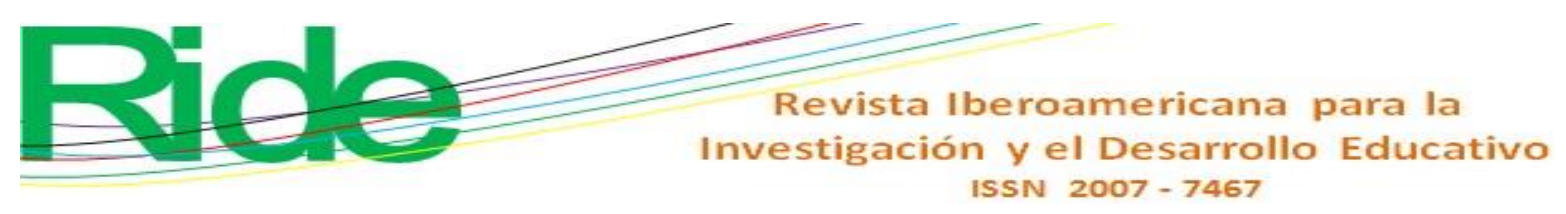

\section{Conclusiones}

Respondiendo a la pregunta de investigación realizada al inicio de esta investigación: ¿Cómo evaluar la implementación del modelo de tutoría virtual para el fortalecimiento de la formación profesional en la Ingeniería en Tecnologías de la Información y de las Comunicaciones? Se evaluó aplicando tres instrumentos distintos. El primero fue la evaluación del proceso continuo, que fue aplicada a los integrantes del Cuerpo Académico de Tutoría, expertos en el tema. El segundo se aplicó a los estudiantes tutorados de Ingeniería en Tecnologías de la Información y de la Comunicación que participaron del pilotaje por medio de la plataforma. Y el tercero fue la revisión de datos estadísticos que nos brindaran un resultado cuantitativo.

A partir de los resultados obtenidos, el proyecto se considera aceptable. Por supuesto hay oportunidades de mejora respecto al uso adecuado de las TIC en conjunto con los elementos andragógicos, didácticos y metodológicos empleados en este proyecto, que si bien han mejorado los resultados de promedio, aprobación y deserción, aún hay posibilidad de un mayor desarrollo.

Una parte importante en la implementación de la tutoría virtual fueron las estrategias didácticas aplicadas, ya que le ofrecen al tutorado diversas posibilidades: desde aquellas que están enfocadas principalmente en lo individual hasta las que buscan el trabajo colaborativo entre los diferentes participantes. Aunque $65.57 \%$ de los estudiantes tutorados que participaron en el pilotaje de la plataforma de tutoría virtual están totalmente de acuerdo con el proyecto, aún consideramos necesario incrementar el grado de satisfacción.

En este proyecto se promovieron sobre todo las actividades que ayudarán a que los tutorados dejaran de ser pasivos y se volvieran activos, y también a que el aprendizaje no se refiera exclusivamente a un almacenamiento memorístico de la información, sino más bien que esté diseñado para hacer una estructuración cognitiva. Otra consideración importante de apoyo en la formación profesional fue incluir actividades que fomentaran el aprendizaje colaborativo y cooperativo como los chats y foros implementados, especialmente porque en la carrera de Ingeniería en Tecnologías de la Información y de la Comunicación es muy común el trabajo en equipo. Hay que destacar que hoy en día los entornos virtuales de aprendizaje han dejado de ser de manera progresiva solo un repositorio de información a convertirse en una herramienta social para la compartición de conocimiento. 


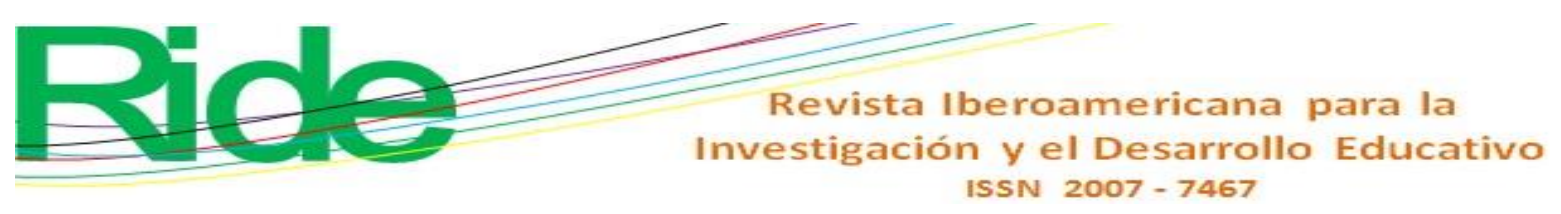

Kerlinger, E. N. (1979). Diseños no experimentales de investigación. En Enfoque conceptual de la investigación del comportamiento. Ciudad de México, México: Nueva Editorial Interamericana.

Marroquín, M. y Forzante, A. (s. f.). La teoría constructivista del aprendizaje. Fundamento para la acción tutorial. Instituto Politécnico Nacional.

Medina, A., Domínguez, M. y Sánchez, C. (2011). La comunicación didáctica en la tutoría virtual. Campinas, 12(núm. esp.), 12-30. Recuperado de https://www.researchgate.net/publication/50985337_La_comunicacion_didactica_en_la_t utoria_virtual_Didactic_communication_in_virtual_tutoring_Comunicacao_didatica.

Pozo, J. (2009). Teorías cognitivas del aprendizaje (5. ${ }^{\mathrm{a}}$ ed.). Madrid, España: Universidad Autónoma de Madrid.

Ramírez, M., Téllez, O. y Díaz, A. (2014). Patrones de usabilidad en los entornos virtuales de aprendizaje. En La era de las TIC en la nueva docencia. México: McGraw-Hill.

Ramírez, M., Téllez, O. y Díaz, A. (2018). Implementación de una plataforma de tutoría virtual en un sistema de gestión de aprendizaje. Revista Iberoamericana de Producción Académica y Gestión Educativa, 5(10).

Rivas, N. (2000). Procesos cognitivos y aprendizaje significativo. Comunidad Madrid. Recuperado de www.madrid.org. 


\begin{tabular}{|c|c|}
\hline Rol de Contribución & Autor (es) \\
\hline Conceptualización & Moramay Ramírez Hernández «igual» Gabriela Figueroa Moreno «igual» \\
\hline Metodología & Moramay Ramírez Hernández \\
\hline Software & Moramay Ramírez Hernández \\
\hline Validación & Omar Téllez Barrientos \\
\hline Análisis Formal & Moramay Ramírez Hernández \\
\hline Investigación & Moramay Ramírez Hernández «igual» Gabriela Figueroa Moreno «igual» \\
\hline Recursos & Omar Téllez Barrientos \\
\hline Curación de datos & Moramay Ramírez Hernández \\
\hline $\begin{array}{l}\text { Escritura - Preparación del borrador } \\
\text { original }\end{array}$ & Moramay Ramírez Hernández \\
\hline Escritura - Revisión y edición & Gabriela Figueroa Moreno «igual» Omar Téllez Barrientos «igual» \\
\hline Visualización & Gabriela Figueroa Moreno \\
\hline Supervisión & Moramay Ramírez Hernández \\
\hline Administración de Proyectos & Moramay Ramírez Hernández «igual» Gabriela Figueroa Moreno «igual» \\
\hline Adquisición de fondos & Moramay Ramírez Hernández «igual» Gabriela Figueroa Moreno «igual» \\
\hline
\end{tabular}

